\title{
"MAGNESIA INJURY" OF PLANTS GROWN IN NUTRIENT SOLUTIONS
}

\author{
W. F. GER I C K E
}

Among the first signs of injury to the tops of wheat seedlings and other cereals grown in nutrient solutions of relatively high (as compared with other salts in solution) concentration of $\mathrm{MgSO}_{4}$, one of the three or more salts commonly used in culture solution experimentation, is that resulting in abscission of the leaf tips of the plants. The progression of this injury consists of wilting, withering, desiccation, and finally abscission. This injury has been found to be most pronounced on young shoots. It also occurs in a much greater degree under conditions conducive for high transpiration of the plants than for low. The term "magnesia injury" has been applied to this peculiar phenomenon of abscission of leaf tips, being so named because usually found associated with comparatively high concentrations of magnesium ion (from $\mathrm{MgSO}_{4}$ ) in nutrient solutions. Additions of soluble calcium salts to nutrient solutions giving injury were often found to be beneficial. This lent support to the concept that a certain calcium-magnesium ratio, or a range thereof, plays an important part in the physiological balance of nutrient solutions.

Recent experiments by the writer appear to bear on this magnesium question. When wheat seedlings were grown in single salt solutions it was found that some cultures gave the typical symptoms and others did not. Briefly, the tests were as follows. Seedlings $6-8 \mathrm{~cm}$. high, with roots $8-10 \mathrm{~cm}$. long, were fitted into and supported on paraffined corks. These were fitted into one quart containers (Mason jars) filled with the single salt solutions to be tested. The solutions were prepared from Baker's C.P. analyzed salts and distilled water. The salts were tested to see whether they conformed to specifications, but no further purification was made. A small amount of $\mathrm{FeSO}_{4}$ (5 drops of o.० I mol solution) was added to the cultures at weekly intervals. The

Botanical Gazette, vol. 74]

[I IO 
cultures were allowed to grow four weeks. Table I gives the experimental data.

The injury sustained by the seedlings grown in the solutions of potassium salts differed with the salts used, being least in the $\mathrm{KH}_{2} \mathrm{PO}_{4}$ set and most marked in that of $\mathrm{K}_{2} \mathrm{SO}_{4}$. Considerable abscission of the leaf tips occurred in the seedlings grown in the solutions of $\mathrm{KNO}_{3}$, although these cultures made by far the best growth (total dry matter production) of any of the nine different salt solutions employed. In marked contrast to these are the results obtained from the cultures grown in the solutions of different calcium salts, none of which gave any symptoms of the characteristic injury. Of the cultures grown in the solutions of magnesium

TABLE I

RELATIVE EFFECTS OF SALTS IN PRODUCING ABSCISSION OF LEAF TIPS OF WHEAT SEEDLINGS

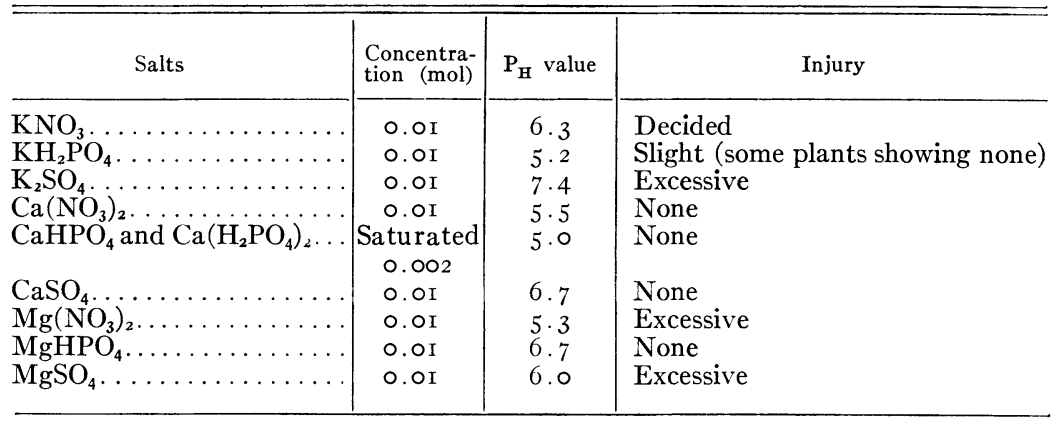

salts, those grown in $\mathrm{Mg}\left(\mathrm{NO}_{3}\right)_{2}$ and $\mathrm{MgSO}_{4}$ were severely injured, but those grown in $\mathrm{MgHPO}_{4}$ were not, being perfectly normal in this respect. While the $\mathrm{P}_{\mathrm{H}}$ values of solutions were not the same, nevertheless it is not evident that this was an important factor to account for the results.

The injury of abscission to the leaf tips of the cultures grown in the solutions of potassium salts appeared to be similar in every respect to that of the cultures grown in solutions of $\mathrm{Mg}\left(\mathrm{NO}_{3}\right)_{2}$ or $\mathrm{MgSO}_{4}$. Whether it was physiologically the same cannot be stated at this time. If the injury to these seedlings was physiologically the same, it appears that there are at least two factors apparent in the data that are related to this injury of abscission of leaf tips, as follows: 
I. The lack of or the deficiency of calcium in the nutrient media. It is in this sense that the injury to the seedlings grown in the solutions of potassium salts is to be accounted for, as it was obviously not due to the presence of magnesium. Furthermore, as the cultures grown in the different solutions of calcium salts were not injured, this is suggestive that beneficial results should obtain from additions of calcium salts to nutrient solutions that have shown themselves to be poor media for plant growth because of excessive amounts of potassium or magnesium salts. Numerous tests have proved this to be true. This, however, does not necessarily imply any definite calcium-magnesium ratio or a calciumpotassium ratio as a condition of physiological importance in nutrient solutions. The amount of calcium ions needed to overcome the harmful effects of excessive concentrations of potassium ions or magnesium ions will be determined largely by other conditions or sets of conditions under which the plants grow, of which those affecting the rate of transpiration of the plants are not of least importance.

2. The relation of phosphorus. A relatively high concentration of magnesium ion and the absence of calcium (except a trace as an impurity) in the solutions are conditions supposed to be conducive to injury. As no abscission of the leaf tips appeared in the seedlings grown in solutions of $\mathrm{MgHPO}_{4}$, it appears that in the magnesium-phosphorus relation is a condition that in this case is physiologically important. It is hardly possible that the trace of calcium found in $\mathrm{MgHPO}_{4}$ could account for these results. Equally large traces of calcium were found in the other salts used, especially $\mathrm{K}_{2} \mathrm{SO}_{4}$, which contained 0.005 per cent. As this amount did not prevent injury, it seems reasonable to discount the effect of a smaller trace of calcium found in $\mathrm{MgHPO}_{4}$ as being the cause for the non-injury to the seedlings. The fact that $\mathrm{KH}_{2} \mathrm{PO}_{4}$ produced less injury than did any of the other potassium salts used presumably was due to some action involving the $\mathrm{H}_{2} \mathrm{PO}_{4}$ ion.

As the potassium salts and two of the magnesium salts used gave injury to the wheat seedlings, one can infer that this was due to some action of a positive ion of the salts in solution. On the other hand, certain positive ions, calcium for example, did not 
produce injury. It does, as has been shown in other experiments, prevent injury where magnesium ions are excessive. The harmful effect of some of the positive ions, however, can also be prevented or greatly mitigated by the presence of certain negative ions. The phosphate ion comes in this category in the cases of the $\mathrm{MgHPO}_{4}$ and $\mathrm{KH}_{2} \mathrm{PO}_{4}$ in this experiment, the former salt producing no injury and the latter salt only a little. Under certain conditions, therefore, it may be expected that additions of phosphate salts should prove beneficial to nutrient solutions that are toxic due to excessive concentrations of either magnesium or potassium. This the writer has found to be the case in other experiments.

No reference has been made to the literature, as this is to be taken up later when the subject will be discussed in greater detail.

University of California 